\title{
Decreased Nucleoside Transport and hENT1 Transporter Expression in Beta-Thalassemia Major
}

\author{
Arwa Lufti Al-Massaeid James D. Craik \\ Department of Biochemistry, Faculty of Medicine, Health Sciences Center, Kuwait University, Kuwait
}

\section{Key Words}

$\beta$-Thalassemia - Erythrocyte $\cdot$ Nucleoside transporter ·

Uridine uptake

\begin{abstract}
Objective: This study investigated nucleoside transport activity and transporter polypeptide expression in erythrocytes from $\beta$-thalassemia major patients to determine if inhibition of transport activity is a sensitive indicator of oxidative membrane damage. Materials and Methods: Blood samples were obtained from 54 patients, diagnosed as having $\beta$-thalassemia major prior to therapeutic transfusion, and 20 normal subjects. Uptake of ${ }^{3} \mathrm{H}$-uridine into washed erythrocytes was measured at room temperature using short incubation periods (5 s) and a rapid inhibitor oil stop protocol. Erythrocyte membranes were analyzed by SDSPAGE and nucleoside (hENT1) and glucose (GLUT-1) transporter polypeptides quantitated on immunoblots. Results: Uridine uptake was significantly lower in $\beta$-thalassemic cells than in normal erythrocytes $\left(20.03 \pm 1.08 \mathrm{pmol} / 10^{8}\right.$ cells/ $5 \mathrm{~s}$, mean $\pm \mathrm{SEM}, \mathrm{n}=31$, vs. $31.15 \pm 1.21 \mathrm{pmol} / 10^{8} \mathrm{cells} / 5 \mathrm{~s}$, $\mathrm{n}=20 ; \mathrm{p}<0.0001)$. Expression of hENT1 was significantly lower in $\beta$-thalassemic cells $(23.90 \pm 1.01$ arbitrary units, $\mathrm{n}=54)$ than in controls (101.20 \pm 2.43 arbitrary units, $\mathrm{n}=20$; $p<0.001$ ) but expression of GLUT-1 was not changed appreciably (101.80 \pm 2.43 arbitrary units, $n=54$, for thalassemic
\end{abstract}

cells; $102.60 \pm 3.02$ arbitrary units, $n=20$, for control cells; $p=0.87$ ). Conclusions: Erythrocytes from $\beta$-thalassemia major patients showed decreased uridine transport which was associated with decreased nucleoside transporter expression. The process(es) mediating a selective decrease in hENT1 polypeptides in $\beta$-thalassemia major was/were not determined.

Copyright $\odot 2009$ S. Karger AG, Basel

\section{Introduction}

$\beta$-Thalassemia is an inherited red cell hemoglobinopathy characterized by a deficiency in $\beta$-globin polypeptide chains, presenting in $\beta$-thalassemia major as anemia with microcytic and hypochromic red cells. This condition is relatively common in populations indigenous to the Arabian Gulf region, including Kuwait [1, 2], as well as in sub-Saharan Africa, the Mediterranean region, and much of South and Southeast Asia. Molecular defects leading to this condition show remarkable heterogeneity; approximately 200 different mutations have been identified to date as reviewed by Weatherall [3]. The continued presence of high rates of deleterious mutations leading to inherited hemoglobinopathies within specific populations has long been a subject for scientific speculation, and the proposal by Haldane [4] that a selective pressure

Dr. James D. Craik

Biochemistry Department

Faculty of Medicine, Health Sciences Center

PO Box 24923, Safat 13110 (Kuwait)

Tel. +965 498 6438, Fax +965 533 8908, E-Mail james@hsc.edu.kw 
imposed by malaria is important in maintaining these polymorphisms, has remained a very useful working hypothesis [5, 6], although proof of specific molecular mechanisms has been difficult to obtain. Possible features include increased erythrocyte surface expression of parasite-associated antigens, increased phagocytosis by monocytes and increased binding of immunoglobulins and complement proteins [7]. In the absence of a single prominent mechanism, it appears likely that interplay between multiple factors may be required to produce the protective effects suggested by epidemiological studies. The protozoan parasite is incapable of de novo purine biosynthesis and is therefore reliant upon the host cell and its extracellular environment for a supply of purines, a feature that makes purine salvage pathways an attractive chemotherapeutic target $[8,9]$. In addition, the parasites are susceptible to intracellular oxidative stress [10] which is increased in thalassemic erythrocytes.

Physiological nucleosides are predominantly hydrophilic in character, so passive diffusion of these compounds across biological membranes is slow. Nucleoside transport in human erythrocytes has been the subject of investigation over the last half-century, and numerous studies have demonstrated and functionally characterized a facilitated diffusion transport process notable for its sensitivity towards inhibition by nanomolar concentrations of nitrobenzylthioinosine [11, 12]. Nucleosidetransport-associated polypeptides were identified as erythrocyte band 4.5 proteins (nomenclature of Steck [13]) by photoaffinity labeling with radiolabeled nitrobenzylthioinosine [14], and transport was later shown to be mediated by an integral membrane glycoprotein, hENT1, that was cloned and sequenced [15] and further characterized by heterologous expression [16]. In mammalian erythrocytes, nucleoside transport can support both energy metabolism and the maintenance of purine nucleotide pools $[17,18]$. The group of Gero $[19,20]$ reported that adenosine uptake was reduced in erythrocytes from patients in Australia and Myanmar diagnosed as having $\beta$-thalassemia but did not identify a specific cause for this change. Nucleoside transport activity in normal erythrocytes is readily inhibited by treatment with low concentrations of diamide [21], consistent with the idea that activity of hENT1 might be a sensitive indicator of membrane effects of oxidative stress in erythrocytes. The aim of this study was to test this hypothesis by investigation of nucleoside transport, using uridine as a poorly metabolized nucleoside permeant, and determination of hENT1 protein expression in erythrocytes from $\beta$-thalassemia major patients.

$\beta$-Thalassemia Nucleoside Transport

\section{Materials and Methods}

\section{Materials}

Phosphate-buffered saline (PBS) was prepared as $137 \mathrm{~mm}$ $\mathrm{NaCl}, 2.7 \mathrm{mM} \mathrm{KCl}, 4.3 \mathrm{mM} \mathrm{Na}_{2} \mathrm{HPO}_{4}$ and $1.76 \mathrm{mM} \mathrm{KH}_{2} \mathrm{PO}_{4}, \mathrm{pH}$ 7.4. Percoll density medium was obtained from Amersham Pharmacia Biosciences, UK. Electroblotting transfer buffer was prepared as $25 \mathrm{~mm}$ Tris, $192 \mathrm{~mm}$ glycine, $\mathrm{pH} 8.3$, and $10 \%$ (v/v) methanol. Radiotracer uridine $\left[6,6{ }^{-3} \mathrm{H}\right], 37 \mathrm{Ci} / \mathrm{mmol}$, was from MP Biomedical (formerly ICN), USA. The protease inhibitor phenylmethylsulfonyl fluoride and the protease inhibitor cocktail Sigma product P.2714 were from Sigma Chemical Co., USA. Dilazep was a generous donation from Hoffman-La Roche Ltd., Ontario, Canada.

Subjects and Samples

Blood samples ( $2 \mathrm{ml}$ up to a maximum volume of $5 \mathrm{ml}$ in heparin or acid citrate dextrose anticoagulant) were obtained with informed consent along with blood samples used for routine hematological monitoring from 54 patients with a diagnosis of $\beta$ thalassemia major presenting prior to therapeutic transfusion. The date of previous transfusion (if applicable) ranged from 3 weeks to 2 months. The age range of donors was 15-35 years. Samples were cooled on ice immediately after collection (AlSabah or Mubarak Al-Kabeer Hospital, Kuwait) and transported to the laboratory for processing on the day of collection. Single patient samples were used for both uridine transport assay and membrane protein analysis; in some cases of smaller clinical samples, membrane analysis was performed without transport assay. Uridine uptake measurements were performed in 31 of the 54 thalassemic blood samples subjected to erythrocyte membrane protein analysis. Control samples were obtained from 20 volunteers, age range 15-60 years, from blood donors attending the Central Blood Bank, Jabriya, Kuwait; they were of Arab ethnicity, mostly of Kuwaiti nationality.

\section{Processing of Blood Samples}

Blood samples were subjected to centrifugation $(500 \mathrm{~g}, 10$ min) on a Percoll density step gradient (density $1.095 \mathrm{~g} / \mathrm{ml}$, isotonic PBS) to remove plasma proteins, platelets and white blood cells, and to deplete the samples of reticulocytes. Following centrifugation, the red cell fraction was washed twice (resuspension in PBS and centrifugation, $500 \mathrm{~g}, 5 \mathrm{~min}$ ) to give an erythrocyte preparation depleted of Percoll. For uridine uptake measurements, cell suspensions of about $30 \%$ hematocrit in PBS were prepared. Erythrocyte counts of cell suspensions were performed manually using a hemocytometer (Hycor, Fisher Scientific, UK). Reticulocyte counts were obtained manually after staining with Brilliant cresyl blue using standard hematological protocols (National Committee for Clinical Laboratory Standards, 1985) or by use of an automated hematological analyzer (Beckman Coulter GEN-S, USA) and were in the range of $0.34-3.4 \%$ of total cell counts.

\section{Red Cell Membrane Preparation}

Red cell membranes were prepared by a conventional hypotonic cell lysis protocol [22]. Briefly, washed erythrocytes (see above) were lysed in 20-50 vol of ice-cold buffer ( $5 \mathrm{mM}$ phosphate, $\mathrm{pH}$ 8.0) in the presence of $0.1 \mathrm{~mm}$ phenylmethylsulfonyl fluoride and a commercial cocktail of protease inhibitors; the cocktail was 
diluted (50 $\mu \mathrm{l} / 100 \mathrm{ml})$ in lysis medium, and phenylmethylsulfonyl fluoride was added immediately prior to addition of erythrocytes. Membranes were collected by high-speed centrifugation (15 min, approx. 26,000 g, Beckman JA-20 rotor), and the supernatant was discarded. Membranes were washed by repeated (usually 5-6 times) resuspension and centrifugation until an off-white membrane preparation was obtained. Protein concentrations were estimated by the method of Lowry et al. [23] using bovine serum albumin as a standard. Membranes were stored as aliquots in $5 \mathrm{~mm}$ phosphate, $\mathrm{pH} 8.0$, at $-80^{\circ} \mathrm{C}$ prior to electrophoretic analysis.

\section{Assay of Uridine Transport in Human Erythrocytes}

Uptake of ${ }^{3} \mathrm{H}$-uridine for short time periods at room temperature was measured using a conventional 'inhibitor oil stop' protocol [24]. Briefly, 50- $\mu$ l portions of silicone oil mixture (density $1.034 \mathrm{~g} / \mathrm{ml}$; Dow Corning 550 and 200/1c mixed in a ratio of $86: 14)$ were placed in $1.5-\mathrm{ml}$ microcentrifuge tubes and $50-\mu l$ portions of erythrocyte suspension (approx. 30\% hematocrit) introduced as a single drop upon the oil layer. Uridine stock solution $(100 \mu \mathrm{M})$ in PBS containing ${ }^{3} \mathrm{H}$-uridine radiotracer at a concentration of $2 \mu \mathrm{Ci} / \mathrm{ml}$ was prepared. Transport was initiated by rapid addition of uridine tracer solution (giving a final concentration of $73 \mu \mathrm{M}$ ) and terminated after a precise interval by rapid addition of $500 \mu \mathrm{l}$ ice-cold 'stopper' solution ( $40 \mu \mathrm{M}$ dilazep in PBS) followed by immediate centrifugation (Eppendorf centrifuge 54215C, full speed, i.e. approx. 14,000 g) for $1 \mathrm{~min}$ to generate a red cell pellet separated by a layer of silicone oil from supernatant fluid. Supernatant fluid was carefully removed and the tube above the oil layer washed by careful addition and removal of about $1 \mathrm{ml}$ distilled water. After removal of oil, the erythrocyte pellet was disrupted by addition of $200 \mu 10.5 \%$ (v/v) Triton X-100 in distilled water and vortex mixing. Protein was precipitated by addition of $200 \mu \mathrm{l}$ of $5 \%(\mathrm{w} / \mathrm{v})$ trichloroacetic acid and brief vortex mixing, and the precipitate was pelleted by centrifugation (full speed, $4 \mathrm{~min}$ ). A $300-\mu \mathrm{l}$ portion of the supernatant was mixed with $3 \mathrm{ml}$ scintillation fluid (Aquasol-2, Beckman Instruments, USA), and radioactivity was determined using a Beckman LS 6000TA scintillation counter. Radioactivity associated with extracellular medium trapped in the erythrocyte pellet was estimated from tubes in which 'stopper' solution was added immediately prior to uridine tracer addition or the addition of erythrocyte suspension to a mixture of uridine and stopper solution. Uptake of uridine after $5 \mathrm{~s}$ of incubation was determined as the mean of quadruplicate measurements.

\section{Electrophoretic Analysis and Immunoblot Protocols}

Membrane proteins were analyzed by SDS-PAGE (10\% polyacrylamide gel, $4 \%$ stacking gel, Laemmli discontinuous buffer system [25], 200 V) after solubilization in sample buffer [62.5 mM Tris, pH 6.8, 2\% (w/v) SDS, 25\% (v/v) glycerol, 0.01\% (w/v) bromophenol blue in the presence of $\beta$-mercaptoethanol $5 \%(\mathrm{v} / \mathrm{v})]$. Protein loadings varied between 3 and $26 \mu \mathrm{g} / \mathrm{lane}$. For each analysis, replicate gels were prepared with one being used for SDS-PAGE analysis and two others for immunoblots. Proteins were transferred to polyvinylidine difluoride membranes $(0.45 \mu \mathrm{m}$ pore size, Millipore Immobilon-P, Millipore, USA, or Bio-Rad, USA) overnight at $30 \mathrm{~V}$ in a cold room $\left(6-8^{\circ} \mathrm{C}\right)$.

SDS-PAGE gels were stained with Coomassie blue R-250 $[0.25 \%(\mathrm{w} / \mathrm{v})$ in $50 \%$ methanol $(\mathrm{v} / \mathrm{v}), 10 \%$ acetic acid $(\mathrm{v} / \mathrm{v})]$ and de- stained [5\% (v/v) methanol, 7.5\% (v/v) acetic acid] prior to scanning densitometry (Syngen Bioimaging Systems).

\section{Immunoblot Analysis}

Proteins were detected by probing blots first with a murine monoclonal antibody specific for hENT1 (antibody 10D7G2 [26]), then, after detection of hENT1 polypeptides using a chemiluminescence detection system, by stripping the blots and reprobing for GLUT-1 glucose transporter polypeptides (murine monoclonal antibody 64C7 [27]).

Briefly, after electrophoretic transfer of proteins, blots were allowed to dry at room temperature. Dried blots were stored at $-20^{\circ} \mathrm{C}$ until analysis. Blots were wetted with methanol, washed briefly in distilled water and equilibrated with PBS. Protein bands were visualized by reversible staining with Ponceau $S$ in $1 \%$ acetic acid and destaining in PBS. Membranes were blocked using a solution of $5 \%$ nonfat milk powder dissolved in $0.2 \%(\mathrm{v} / \mathrm{v})$ Tween 20, $20 \mathrm{~mm}$ Tris-HCl, pH 7.6, and $137 \mathrm{mM} \mathrm{NaCl}$, incubated with primary antibody diluted in blocking solution at $4-6^{\circ} \mathrm{C}$ with gentle agitation (orbital mixer) for 4-18 h. After extensive washing $(0.05 \%$ Tween 20 in PBS, ice-cold) membranes were incubated (2-4h) with peroxidase-conjugated goat anti-mouse IgG (Fab specific; Sigma 2304, Sigma Chemical Co.) or an anti-mouse IgG peroxidase conjugate supplied with ECL plus reagent kit (Amersham Biosciences). Blots were washed (0.05\% Tween 20 in PBS, ice-cold), and specific binding of antibody was detected using commercial chemiluminescence detection systems (ECL plus, RPN1232 and ECL, RPM 2108 kits, Amersham Biosciences) and Biomax Light Chemiluminescence film (Kodak, USA). Film was developed manually, and band densities were quantitated using a densitometry analysis system (Syngene Chemi Genius Bio Imaging System). After probing with anti-hENT1 antibody, blots were stripped (0.2 M glycine, $\mathrm{pH} 2.8,30 \mathrm{~min}$, room temperature, gentle agitation), washed with PBS and subjected to blocking and immunostaining as described above using antiGLUT-1 antibodies. The level of hENT1 or GLUT-1 protein normalized to total membrane protein in a $\beta$-thalassemia sample or a membrane preparation from a normal subject was compared to dilutions of a standard membrane preparation (a red cell membrane preparation pooled from 2 normal donors and stored in small aliquots at $-80^{\circ} \mathrm{C}$ ) present on the same blot. Experimental controls from which the primary monoclonal antibodies were omitted showed no staining in the band 4.5 region (data not shown).

\section{Data Analysis}

Two identical replicate blots were prepared and analyzed for each membrane sample (from $\beta$-thalassemia patients or control individuals). Results of replicate blots were averaged and the average values used for subsequent analysis. A test of distribution curve was performed: that of hENT1 expression showed that it was almost normally distributed (although the Shapiro-Wilk normality test showed some significance for the patients' group), so it was deemed reasonable to use a parametric test to investigate the changes in hENT1 expression between $\beta$-thalassemia patients and controls. Statistical analysis was performed using SPSS and Graphpad Prism software. $p$ values below 0.05 were considered to be significant. 


\section{Results}

\section{Uridine Uptake}

Control measurements showed a negligible uptake of uridine radiotracer into erythrocytes in the presence of chilled stopper solution over a period of $2 \mathrm{~min}$ (data not shown). Net uridine uptakes at $5 \mathrm{~s}$ in erythrocytes from normal individuals and $\beta$-thalassemia patients are given in figure 1. Net uptake of uridine was significantly lower $(\mathrm{p}<0.0001)$ in $\beta$-thalassemic erythrocytes with $20.03 \pm$ $1.08 \mathrm{pmol} / 10^{8}$ cells $/ 5 \mathrm{~s}$ (mean $\pm \mathrm{SEM}, \mathrm{n}=31$ ) than in erythrocytes from normal individuals $(31.15 \pm 1.21$ $\mathrm{pmol} / 10^{8}$ cells $\left./ 5 \mathrm{~s}, \mathrm{n}=20\right)$. Although all clinical samples were obtained prior to therapeutic transfusion, it is possible that higher transport activity in some samples from $\beta$-thalassemia patients could reflect residual influence of a previous blood transfusion.

\section{Nucleoside and Glucose Transporter Polypeptides}

Chemiluminescence detection of monoclonal antibody binding to hENT1 and GLUT-1 polypeptides demonstrated bands separating in the band 4.5 region on immunoblots (fig. 2). The very broad band of staining for GLUT-1 in human erythrocytes obtained using the monoclonal antibody is consistent with published reports and was of identical mobility to bands detected on immunoblots of normal erythrocyte membranes using a commercial rabbit polyclonal antibody preparation specific for GLUT-1 (Alpha Diagnostics, USA; data not shown). Film exposure times were adjusted to obtain images suitable for densitometric analysis.

A summary of quantitation of hENT1 and GLUT-1 polypeptides is presented as figure 3 . Both $\beta$-thalassemia and control samples were compared to dilutions of a common standard membrane preparation (arbitrarily set as $100 \%$ ), as described in Materials and Methods. Expression of hENT1 polypeptides was significantly lower in $\beta$-thalassemic red cells $(23.90 \pm 1.01$ arbitrary units, $\mathrm{n}=$ 54) than in control cells $(101.20 \pm 2.91$ arbitrary units, $\mathrm{n}=20 ; \mathrm{p}<0.001)$ but expression of GLUT-1 was not changed appreciably $(101.80 \pm 2.42$ arbitrary units, $\mathrm{n}=$ 54 , for thalassemic cells; $102.60 \pm 3.02$ arbitrary units, $\mathrm{n}=20$, for control cells; $\mathrm{p}=0.87$ ).

\section{Discussion}

Uridine transport, as determined by net radiotracer uptake at a single low uridine concentration at room temperature, was significantly lower in washed erythro-

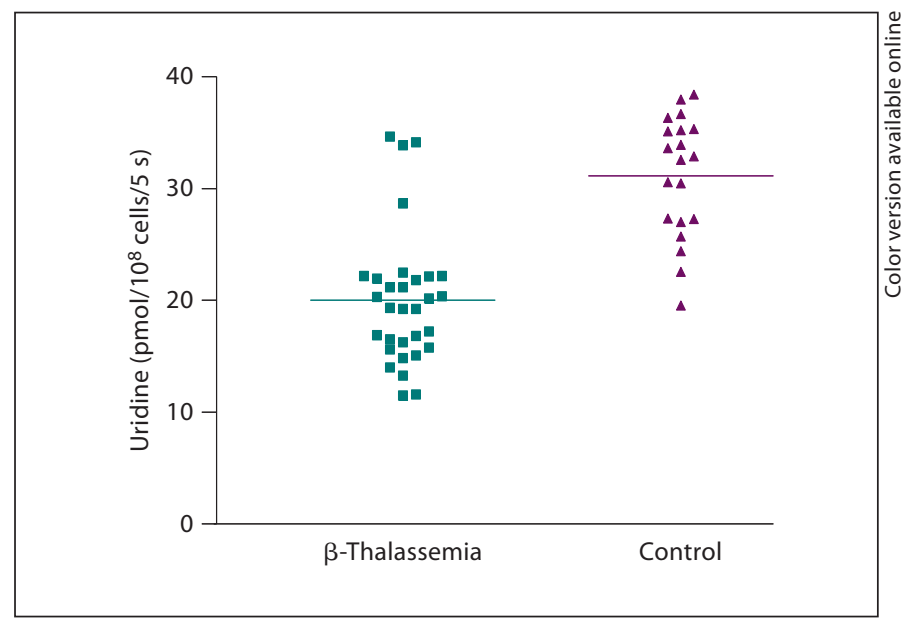

Fig. 1. Uridine uptake after 5-second incubation at room temperature into washed erythrocytes from healthy volunteers (control) and $\beta$-thalassemia major patients. The means are indicated. The difference between $\beta$-thalassemic red cells $(20.03 \pm 1.08$ $\mathrm{pmol} / 10^{8}$ cells $\left./ 5 \mathrm{~s}, \mathrm{n}=31\right)$ compared to control cells $(31.15 \pm 1.21$ $\mathrm{pmol} / 10^{8}$ cells $\left./ 5 \mathrm{~s}, \mathrm{n}=20\right)$ was highly significant $(\mathrm{p}<0.0001)$.

cytes from patients with a diagnosis of $\beta$-thalassemia major than in control cells from healthy volunteers. Uridine is not readily metabolized in human erythrocytes [28], so metabolic effects may be discounted for short incubation periods under these conditions. This significant decrease in uridine transport in thalassemic cells is in concordance with reports of a decreased uptake of radiolabeled adenosine $[19,20]$, a nucleoside that is subject to rapid intracellular metabolism in human erythrocytes, and confirms this to be due to a change in transport activity rather than metabolic properties of the cells. Unfortunately, the small volumes of cells available from the clinical samples (small blood samples from anemic patients) and the division of washed cells for membrane and transport studies prevented a comprehensive kinetic analysis. Use of a short 5-second assay period (selected after examination of the time course of uridine uptake in control cells in which 10-second uptakes were found to give only a slightly lower rate of uridine entry) minimized potential systematic underestimation of the true initial rates of transport due to solute backflow in samples showing the highest uridine permeability. A low concentration of uridine was selected to render the uptake measurements sensitive to a variety of possible changes in transporter properties; under the conditions of measurement, which approximated to a zero trans entry protocol with $[\mathrm{S}]<\mathrm{K}_{\mathrm{m}}$ (extracellular 

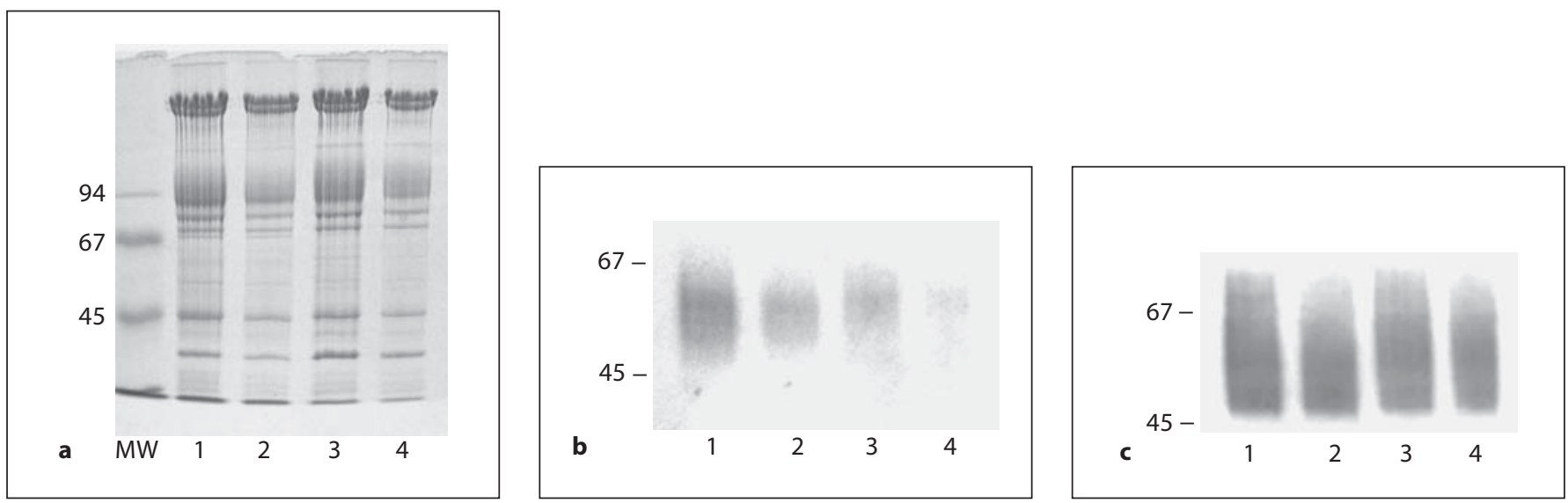

Fig. 2. Comparison of normal and $\beta$-thalassemic erythrocyte membranes by SDS-PAGE (a) and immunoblot probed with antibodies specific for hENT1 (b). The blot shown in $\mathbf{b}$ was subsequently stripped and reprobed with antibodies directed against GLUT-1 polypeptides (c). Lanes 1 and 2: control membrane prep-

aration (12 and $6 \mu \mathrm{g}$ membrane protein); lanes 3 and 4: membrane samples from a $\beta$-thalassemia patient (12 and $6 \mu \mathrm{g}$ membrane protein). Molecular weight (MW) standards: phosphorylase b, bovine serum albumin and ovalbumin.

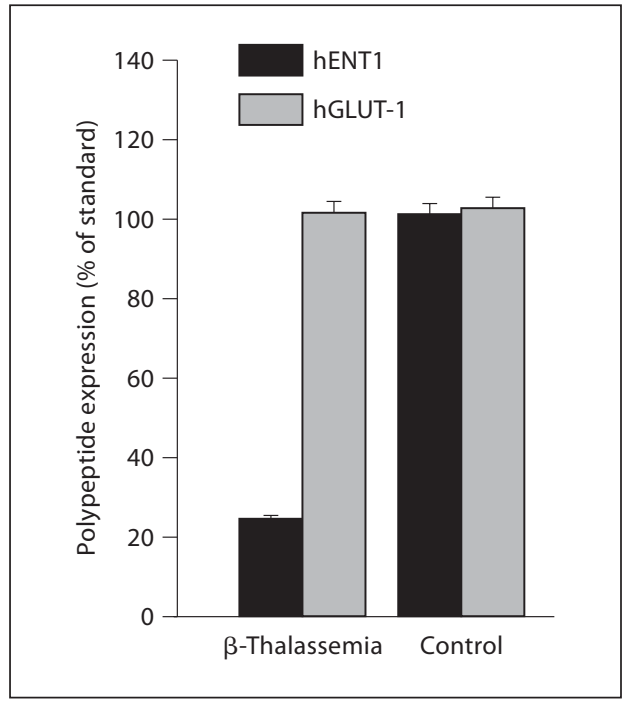

Fig. 3. Expression levels of hENT1 and GLUT-1 polypeptides in erythrocyte membranes from $\beta$-thalassemia patients and control subjects. Transporter polypeptide expression was normalized to total membrane protein, and samples from both $\beta$-thalassemia patients and control subjects were compared to a common standard membrane preparation (arbitrarily set to $100 \%$, vertical axis). Means \pm SEM are represented.

uridine approx. $73 \mu \mathrm{M} ; \mathrm{K}_{\mathrm{m}}$ approx. $170 \mu \mathrm{M}$ at $22^{\circ} \mathrm{C}$ [29]), differences in either $\mathrm{V}_{\max }$ or $\mathrm{K}_{\mathrm{m}}$ (or of coordinate changes in both parameters) of transport could influence initial rates of net uridine uptake.

The discovery that hENT1 nucleoside transporter polypeptides are present at significantly lower levels in $\beta$-thalassemic red cell membranes provides an explanation for the reduction in nucleoside transport rates, although the kinetic data is not sufficient to determine whether transport properties (substrate affinity, turnover number) of the remaining transporters have changed. Abnormalities in protein composition of membranes of $\beta$-thalassemic human erythrocytes have been reported in a number of studies $[30,31]$ but these have largely focused on cytoskeletal proteins and AE-1 anion exchanger (band 3); nutrient transporters have received little attention. Selective reduction of nucleoside transporters in $\beta$ thalassemia patients (glucose transporter expression appears to be unaffected) raises questions with respect to the biological mechanism(s) controlling nutrient transporter expression in these cells. Effects on transcription, translation, posttranslational processing or membrane insertion of the nucleoside transporter protein could be responsible. Alternatively, synthesis could proceed normally but the mature protein might then be subject to enhanced rates of degradation, either through differences in protein binding and stabilization or through more general differences in protease activities in thalassemic red cells. An attractive hypothesis is that in $\beta$-thalassemia major there are disturbances in the sorting of proteins destined to be lost from maturing red cells through the exosome pathway [32], which is thought to involve lipid raft-associated membrane domains [33]. Marked 
disparities have been reported for expression of nutrient transporters in different mammalian species. In maturing sheep reticulocytes, a variety of nutrient transporters, including glucose and nucleoside transporters, are lost $[34,35]$; in adult pigs the mature erythrocyte completely lacks glucose transporters but retains equilibrative nucleoside transport $[36,37]$ while neonatal pig erythrocytes express both GLUT-1 and nucleoside transporters [38].

The finding that hENT1 protein expression is reduced in the $\beta$-thalassemic erythrocyte raises the interesting possibility that aberrant activity of sorting or degradation pathways for integral membrane proteins in maturing erythrocyte precursor cells could be an intrinsic pathological feature of $\beta$-thalassemia major. In addition, changes in hENT1 protein expression may impact the ability of the thalassemic erythrocyte to maintain intracellular purine levels, particularly under conditions of metabolic stress, and could be of significance for the pharmacokinetics of nucleoside drugs in these patients. We believe that this may be the first demonstration of decreased erythrocyte expression of a nutrient transporter to be associated with an inherited hemoglobinopathy.

\section{Conclusion}

The results of this study confirmed a decrease in nucleoside transport activity in $\beta$-thalassemia major erythrocytes as the cause of depression of adenosine uptake in these cells. However, measurements of the expression of the hENT1 protein confound the initial hypothesis that the erythrocyte nucleoside transporter proteins represent a particularly sensitive membrane protein target for inactivation by oxidative stress in human erythrocytes, since decreased nucleoside transport activity is associated with substantially decreased amounts of hENT1 polypeptides in the cell membrane. A selective decline in nutrient transporter polypeptides may be a significant pathological feature of erythrocyte membranes in $\beta$ thalassemia major.

\section{Acknowledgements}

The authors thank Prof. Carol Cass, Department of Oncology, Cross Cancer Institute, University of Alberta, Canada, for generous donation of anti-hENT1 murine monoclonal antibody. We thank Prof. K.C. Das, Department of Pathology, Kuwait University, for assistance with the provision of clinical samples and expert advice on hematological parameters. We thank Dr. Salah AlHumoud and Dr. Hanan Al-Wazzan, Department of Pathology, Kuwait University, for assistance with provision of clinical samples. Dr. Zoran Redzic, Department of Physiology, Kuwait University, is thanked for the critical reading of the manuscript. This study formed part of an MSc thesis submission by Arwa L. AlMassaeid and was supported by a Scholarship from the College of Graduate Studies, Kuwait University. Some reagents used in this study were provided from Kuwait University Research Grant MB 030 (to J.D.C.).

\section{References}

1 Adekile AD, Gu LH, Baysal E, Haider MZ, al-Fuzae L, Aboobacker KC, al-Rashied A, Huisman TH: Molecular characterization of alpha-thalassemia determinants, beta-thalassemia alleles, and beta $S$ haplotypes among Kuwaiti Arabs. Acta Haematol 1994;92:176181.

-2 Adekile AD: Historical and anthropological correlates of beta $S$ haplotypes and alphaand beta-thalassemia alleles in the Arabian Peninsula. Hemoglobin 1997;21:281-296.

$\checkmark 3$ Weatherall DJ: Phenotype-genotype relationships in monogenic disease: lessons from the thalassaemias. Nat Rev Genet 2001;2: 245-255.

4 Haldane JBS: The rate of mutation of human genes. Hereditas 1948;35(suppl):267-273.

5 Carter R, Mendis KN: Evolutionary and historical aspects of the burden of malaria. Clin Microbiol Rev 2002;15:564-594.
6 Kwiatkowski DP: How malaria has affected the human genome and what human genetics can teach us about malaria. Am J Hum Genet 2005;77:171-192.

7 Min-Oo G, Gros P: Erythrocyte variants and the nature of their malaria protective effect. Cell Microbiol 2005;7:753-763.

-8 Kicska GA, Tyler PC, Evans GB, Furneaux RH, Schramm VL, Kim K: Purine-less death in Plasmodium falciparum induced by immucillin- $\mathrm{H}$, a transition state analogue of purine nucleoside phosphorylase. J Biol Chem 2002;277:3226-3231

$\checkmark 9$ el Kouni MH: Potential chemotherapeutic targets in the purine metabolism of parasites. Pharmacol Ther 2003;99:283-309.

10 Muller S: Redox and antioxidant systems of the malaria parasite Plasmodium falciparum. Mol Microbiol 2004;53:1291-1305.
11 Paterson ARP, Oliver JM: Nucleoside transport. II. Inhibition by $p$-nitrobenzylthioguanosine and related compounds. Can J Biochem 1971;49:271-274.

12 Cass CE, Gaudette LA, Paterson ARP: Mediated transport of nucleosides in human erythrocytes: specific binding of the inhibitor nitrobenzylthioinosine to nucleoside transport sites in the erythrocyte membrane. Biochim Biophys Acta 1974;345:1-10.

13 Steck TL: The organization of proteins in the human red blood cell membrane: a review. J Cell Biol 1974;62:1-19.

14 Young JD, Jarvis SM, Robins MJ, Paterson ARP: Photoaffinity labeling of the human erythrocyte nucleoside transporter by N6( $p$-azidobenzyl)adenosine and nitrobenzylthioinosine: evidence that the transporter is a band 4.5 polypeptide. J Biol Chem 1983; 258:2202-2208. 
15 Griffiths M, Beaumont N, Yao SY, Sundaram M, Boumah CE, Davies A, Kwong FY, Coe I, Cass CE, Young JD, Baldwin SA: Cloning of a human nucleoside transporter implicated in the cellular uptake of adenosine and chemotherapeutic drugs. Nat Med 1997;3:8993.

- 16 Baldwin SA, Beal PR, Yao SY, King AE, Cass CE, Young JD: The equilibrative nucleoside transporter family, SLC29. Pflugers Arch 2004;447:735-743.

17 Young JD, Paterson AR, Henderson JF: Nucleoside transport and metabolism in erythrocytes from the Yucatan miniature pig: evidence that inosine functions as an in vivo energy substrate. Biochim Biophys Acta 1985;842:214-224.

- 18 Zeidler RB, Metzler MH, Moran JB, Kim $\mathrm{HD}$ : The liver is an organ site for the release of inosine metabolized by non-glycolytic pig red cells. Biochim Biophys Acta 1985;838: 321-328.

-19 Myint-Oo, Upston JM, Gero AM, O’Sullivan WJ: Reduced transport of adenosine in erythrocytes from patients with beta-thalassaemia. Int J Parasitol 1993;23:303-307.

20 Myint-Oo, O’Sullivan WJ, Gero AM: Laboratory and field comparisons of adenosine influx in Plasmodium falciparum and Plasmodium vivax infected erythrocytes with genetic abnormalities from patients in Myanmar. Southeast Asian J Trop Med Public Health 1997;28:22-31.

-21 Gero AM, Wood AM, Hogue DL, Upston JM: Effect of diamide on nucleoside and glucose transport in Plasmodium falciparum and Babesia bovis infected erythrocytes. Mol Biochem Parasitol 1991;44:195-206.

-22 Dodge JT, Mitchell C, Hanahan D: The preparation and chemical characteristics of hemoglobin-free ghosts of human erythrocytes. Arch Biochem Biophys 1963;100: $109-130$.
23 Lowry OH, Rosebrough NJ, Farr AL, Randall RJ: Protein measurement with the Folin phenol reagent. J Biol Chem 1951;193:265275.

24 Craik JD, Young JD, Cheeseman CI: Nucleoside transport in erythrocytes from bottlenosed dolphin (Tursiops truncatus). Comp Biochem Physiol A Physiol 1997;117:127134.

25 Laemmli UK: Cleavage of structural proteins during the assembly of the head of bacteriophage $\mathrm{T}_{4}$. Nature 1970;227:680-685.

26 Jennings LL, Hao C, Cabrita MA, Vickers MF, Baldwin SA, Young JD, Cass CE: Distinct regional distribution of human equilibrative nucleoside transporter proteins 1 and 2 (hENT1 and hENT2) in the central nervous system. Neuropharmacology 2001; 40:722-731.

27 Good AH, Craik JD, Jarvis SM, Kwong FYP Young JD, Paterson ARP, Cass CE: Characterization of monoclonal antibodies that recognize band 4.5 polypeptides associated with nucleoside transport in pig erythrocytes. Biochem J 1987;244:749-755.

28 Oliver JM, Paterson ARP: Nucleoside transport. I. A mediated process in human erythrocytes. Can J Biochem 1971;49:262-270.

29 Jarvis SM, Hammond JR, Paterson ARP, Clanachan AS: Nucleoside transport in human erythrocytes: a simple carrier with directional symmetry in fresh cells, but with directional asymmetry in cells from outdated blood. Biochem J 1983;210:457-461.

30 Shinar E, Shalev O, Rachmilewitz EA, Schrier SL: Erythrocyte membrane skeleton abnormalities in severe $\beta$-thalassemia. Blood 1987;70:158-164.
31 Rouyer-Fessard P, Garel MC, Domenget C, Guetarni D, Bachir D, Colonna P, Beuzard Y: A study of membrane protein defects and alpha hemoglobin chains of blood cells in human beta thalassemia. J Bol Chem 1989;264: 19092-19098.

32 Johnstone RM: Exosomes biological significance: a concise review. Blood Cells Mol Dis 2006;36:315-321.

33 De Gassart A, Geminard C, Fevrier B, Raposo G, Vidal M: Lipid raft-associated protein sorting in exosomes. Blood 2003;102: 4336-4344.

34 Johnstone RM, Adam M, Hammond JR, Orr L, Turbide C: Vesicle formation during reticulocyte maturation: association of plasma membrane activities with released vesicles (exosomes). J Biol Chem 1987;262:94129420 .

35 Johnstone RM, Mathew A, Mason AB, Teng $\mathrm{K}$ : Exosome formation during maturation of mammalian and avian reticulocytes: evidence that exosome release is a major route for externalization of obsolete membrane proteins. J Cell Physiol 1991;147:27-36.

36 Young JD, Paterson AR, Henderson JF: Nucleoside transport and metabolism in erythrocytes from the Yucatan miniature pig: evidence that inosine functions as an in vivo energy substrate. Biochim Biophys Acta 1985;842:214-224.

37 Zeidler RB, Metzler MH, Moran JB, Kim HD: The liver is an organ site for the release of inosine metabolized by non-glycolytic pig red cells. Biochim Biophys Acta 1985;838: 321-328.

38 Craik JD, Good AH, Gottschalk R, Jarvis SM, Paterson ARP, Cass CE: Identification of glucose and nucleoside transport proteins in neonatal pig erythrocytes using monoclonal antibodies against band 4.5 polypeptides of adult human and pig erythrocytes. Biochem Cell Biol 1988;66:839-852. 